\title{
On the nanometer scale phase separation of a low-supersaturation Ni-Al-Cr alloy
}

\author{
Christopher Booth-Morrison ${ }^{\mathrm{a}}$, Yang Zhou ${ }^{\mathrm{a}}$, \\ Ronald D. Noebe ${ }^{\mathrm{b}}$ and David N. Seidman ${ }^{\mathrm{a}, \mathrm{c} *}$ \\ ${ }^{a}$ Department of Materials Science and Engineering, Northwestern University, \\ 2220 Campus Drive, Evanston, IL 60208-3108, USA; ${ }^{\circ}$ NASA Glenn Research Center, \\ 21000 Brookpark Rd., Cleveland, OH 44135, USA; ${ }^{c}$ Northwestern University Center \\ for Atom-Probe Tomography (NUCAPT), 2220 Campus Drive, \\ Evanston, IL 60208-3108, USA
}

(Received 14 November 2008; final version received 9 February 2009)

\begin{abstract}
The phase separation of a $\mathrm{Ni}-6.5 \mathrm{Al}-9.5 \mathrm{Cr}$ at. \% alloy aged at $873 \mathrm{~K}$ was studied by atom-probe tomography and compared to the predictions of classical precipitation models. Phase separation in this alloy occurs in four distinct regimes: (i) quasi-stationary-state $\gamma^{\prime}\left(\mathrm{Ll}_{2}\right)$-precipitate nucleation; (ii) concomitant precipitate nucleation, growth and coagulation and coalescence; (iii) concurrent growth and coarsening, wherein coarsening occurs via both $\gamma^{\prime}$-precipitate coagulation and coalescence and by the classical evaporation-condensation mechanism; and (iv) quasi-stationarystate coarsening of $\gamma^{\prime}$-precipitates, once the equilibrium volume fraction of precipitates is achieved. The predictions of classical nucleation and growth models are not validated experimentally, likely due to the complexity of the atomistic kinetic pathways involved in precipitation. During coarsening, the temporal evolution of the $\gamma^{\prime}$-precipitate average radius, number density and the $\gamma(\mathrm{fcc})$-matrix and $\gamma^{\prime}$-precipitate supersaturations follow the predictions of classical models.
\end{abstract}

Keywords: nickel-based superalloy; phase decomposition; atom probe tomography; temporal evolution; nanostructure

\section{Introduction}

Efforts to improve the fuel efficiency of aviation fuel and natural gas burning turbine engines have led to the development of complex concentrated multicomponent nickel-based superalloys that can withstand the extreme environments inside these engines [1,2]. Nickel-based superalloys are used in sections of turbine engines where operating temperatures exceed $1073 \mathrm{~K}$, and resistance to chemical and mechanical degradation is critical. The high-temperature mechanical properties of these alloys depend primarily on the presence of coherent, elastically-hard, $\mathrm{L1}_{2}$-ordered $\gamma^{\prime}$-precipitates that result from decomposition of the $\gamma(\mathrm{fcc})$ matrix.

Recent investigations of $\gamma^{\prime}$-precipitation in model $\mathrm{Ni}-\mathrm{Al}-\mathrm{Cr}$ superalloys employing atom-probe tomography (APT) have elucidated the kinetic pathways of phase

\footnotetext{
*Corresponding author. Email: d-seidman@northwestern.edu
} 
separation for two alloys, Ni-7.5 Al-8.5 $\mathrm{Cr}$ and $\mathrm{Ni}-5.2 \mathrm{Al}-14.2 \mathrm{Cr}$ at. \%, both of which have a $\gamma^{\prime}$-phase volume fraction of about $16 \%$ [3-10]. These studies have, however, been limited by both the number of $\gamma^{\prime}$-precipitates investigated, and by the number of data points collected during the $\gamma^{\prime}$-precipitate nucleation and growth regimes. Recent advances in APT have improved the data collection rate and the field-of-view $\left(200 \times 200 \mathrm{~nm}^{2}\right.$ at the lowest magnification $)$ of this technique [11-13], thereby eliminating the problems associated with an insufficient $\gamma^{\prime}$-precipitate sample size.

Details are presented of the phase separation of a low-supersaturation Ni-6.5 Al-9.5 $\mathrm{Cr}$ at. $\%$ alloy aged at $873 \mathrm{~K}$. This alloy was chosen to employ a small chemical driving force for nucleation, permitting a detailed study of precipitate nucleation, and subsequently growth and coarsening. The reduced $\gamma$-matrix supersaturation also results in a smaller $\gamma^{\prime}$-precipitate volume fraction, making this alloy more amenable to comparison with the predictions of classical models of phase separation. A ternary $\mathrm{Ni}-\mathrm{Al}-\mathrm{Cr}$ phase diagram determined by the grand canonical Monte Carlo (GCMC) technique at $873 \mathrm{~K}$ (Figure 1) predicts that the value of the equilibrium volume fraction, $\phi^{e q}$, for $\mathrm{Ni}-6.5 \mathrm{Al}-9.5 \mathrm{Cr}$ at. $\%$ aged at $873 \mathrm{~K}$ is $10.2 \pm 0.5 \%$. Ni-7.5 $\mathrm{Al}-8.5 \mathrm{Cr}$ and $\mathrm{Ni}-5.2 \mathrm{Al}-14.2 \mathrm{Cr}$ at. \%, the other $\mathrm{Ni}-\mathrm{Al}-\mathrm{Cr}$ alloys that have been investigated in detail by APT, which are also plotted

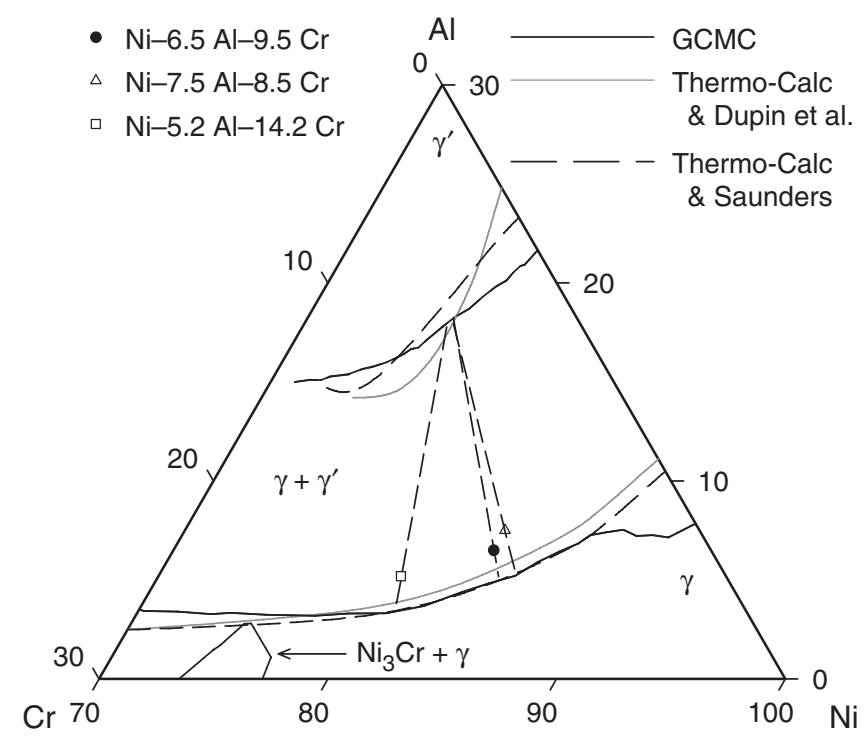

Figure 1. A partial ternary phase diagram of the $\mathrm{Ni}-\mathrm{Al}-\mathrm{Cr}$ system at $873 \mathrm{~K}$ calculated using the grand canonical Monte Carlo (GCMC) simulation technique [14], showing the proximity of $\mathrm{Ni}-6.5 \mathrm{Al}-9.5 \mathrm{Cr}$ at. $\%$ to the $\left(\gamma+\gamma^{\prime}\right) / \gamma$ solvus line. Two other alloys that have been investigated by APT, Ni-7.5 Al-8.5 $\mathrm{Cr}$ and $\mathrm{Ni}-5.2 \mathrm{Al}-14.2 \mathrm{Cr}$ at. \%, are shown for comparative purposes. Equilibrium solvus curves determined by Thermo-Calc [25], using databases for nickel-based superalloys due to Saunders [26] and Dupin et al. [27], are superimposed on the GCMC phase diagram. The tie-lines are determined from the equilibrium phase compositions, determined by extrapolation of APT concentration data to infinite time. 
in Figure 1, are predicted to have values of $\phi^{e q}$ of $17.5 \pm 0.5$ and $15.1 \pm 0.5 \%$, respectively $[3,14]$.

\section{Experimental}

High-purity $\mathrm{Ni}, \mathrm{Al}$ and $\mathrm{Cr}$ were induction-melted under a partial pressure of $\mathrm{Ar}$ and chill cast in a $19 \mathrm{~mm}$ diameter copper mold to form a polycrystalline master ingot. The overall composition of the master ingot was determined by inductively coupled plasma atomic-emission spectroscopy to be $84.12 \mathrm{Ni}-6.24 \mathrm{Al}-9.64 \mathrm{Cr}$ at. \%, and was indistinguishable, within experimental error, from the targeted composition of $\mathrm{Ni}-6.5 \mathrm{Al}-9.5 \mathrm{Cr}$ at. \% . Samples from the ingot were subjected to a three-stage heat-treatment: (1) homogenization at $1573 \mathrm{~K}$ in the $\gamma$-phase field for $20 \mathrm{~h}$; (2) a vacancy anneal in the $\gamma$-phase field at $1123 \mathrm{~K}$ for $3 \mathrm{~h}$ followed by a water quench; and (3) an aging anneal at $873 \mathrm{~K}$ under flowing argon for times ranging from 0.25 to 4096 h, followed by a water quench. Pulsed-laser APT was performed with a 3-D LEAP tomograph [11,15-18] at a target evaporation rate of 0.04 ions per pulse, a specimen temperature of $40.0 \pm 0.3 \mathrm{~K}$, a pulse energy of $0.6 \mathrm{~nJ}$ per pulse, a pulse repetition rate of $200 \mathrm{kHz}$ and an ambient gauge pressure of less than $6.7 \times 10^{-8} \mathrm{~Pa}$. These evaporation conditions have been optimized to provide the highest compositional accuracy for this alloy [19]. APT data were analyzed with the software program IVAS 3.0 (Imago Scientific Instruments). The $\gamma^{\prime}$-precipitate/ $\gamma$-matrix heterophase interfaces were delineated with Al isoconcentration surfaces employing the inflection point method [20], and compositional information was obtained using the proximity histogram methodology [21,22]. The standard errors for all quantities are calculated based on counting statistics, and represent two standard deviations from the mean [23]. We note that spatial convolution effects such as ion-trajectory overlap and local magnification effects, which have been cited as sources of misleading results in APT analysis of nickel-based superalloys [24], are not significant for low-supersaturation $\mathrm{Ni}-\mathrm{Al}-\mathrm{Cr}$ alloys aged at $873 \mathrm{~K}$ [3]. Further experimental details are provided in references [3,4]; the same procedures were employed herein.

For comparative purposes, the equilibrium phase boundaries determined by the software program Thermo-Calc [25], using the thermodynamic databases due to Saunders [26] and Dupin et al. [27], are superimposed on the phase diagram at $873 \mathrm{~K}$ (Figure 1) [28]. Whereas the generated $\gamma /\left(\gamma+\gamma^{\prime}\right)$ solvus lines show good agreement, the curvatures of the $\gamma+\left(\gamma^{\prime} / \gamma^{\prime}\right)$ phase lines differ for each technique. We note a discrepancy between the $\left(\gamma+\gamma^{\prime}\right) / \gamma$ solvus lines predicted by Thermo-Calc and the GCMC technique as they approach the binary $\mathrm{Ni}-\mathrm{Al}$ axis. Given that GCMC employs changes in chemical potentials to determine the equilibrium tie-line compositions, it is unlikely that this discrepancy is an artifact of the simulation, and may be due to the fitting involved in the design of Thermo-Calc databases.

All thermodynamic quantities used herein were obtained from the commercial software package Thermo-Calc [25] using thermodynamic databases due to Saunders [26] and Dupin et al. [27]. The tracer diffusivities of the atomic species in the $\gamma$-matrix phase were calculated employing Dictra [29] with the mobility database due to Campbell et al. [30] and employing the Saunders thermodynamic database. 


\section{Results and discussion}

\subsection{Morphological evolution}

The temporal evolution of the $\gamma^{\prime}$-precipitate morphology of the model $\mathrm{Ni}-\mathrm{Al}-\mathrm{Cr}$ alloy is displayed in a series of $25 \times 25 \times 200 \mathrm{~nm}^{3}$ 3D-APT reconstructions, each containing ca. 5.5 million atoms (Figure 2). Nanometer-sized spheroidal $\gamma^{\prime}$-precipitates are detected in $\mathrm{Ni}-6.5 \mathrm{Al}-9.5 \mathrm{Cr}$ at. $\%$ for aging times ranging from 0.5 to $1024 \mathrm{~h}$. The $\gamma^{\prime}$-precipitates at an aging time of $4096 \mathrm{~h}$ have commenced a spheroidal-to-cuboidal morphological transformation to minimize their elastic strain energy as they increase in size [31-33]. For aging times of 1.5 to $64 \mathrm{~h}, \gamma^{\prime}$-precipitate coagulation and coalescence is evident, characterized by the formation of $\mathrm{L1}_{2}$-ordered necks that interconnect $\gamma^{\prime}$-precipitates. Precipitate coagulation and coalescence has been detected previously in two different $\mathrm{Ni}-\mathrm{Al}-\mathrm{Cr}$ alloys [3,4], and is due to the overlap of the non-equilibrium $\gamma^{\prime}$-precipitate diffusion fields caused by the specific coupling among diffusion fluxes of $\mathrm{Ni}, \mathrm{Al}$, and $\mathrm{Cr}$ toward and away from $\gamma^{\prime}$-precipitates [34].

\subsection{Temporal evolution of the nanostructural properties of the $\gamma^{\prime}$-precipitates}

The temporal evolution of $\mathrm{Ni}-6.5 \mathrm{Al}-9.5 \mathrm{Cr}$ at. $\%$ aged at $873 \mathrm{~K}$ is complex and is divided into four regimes: (i) quasi-stationary-state $\gamma^{\prime}$-precipitate nucleation

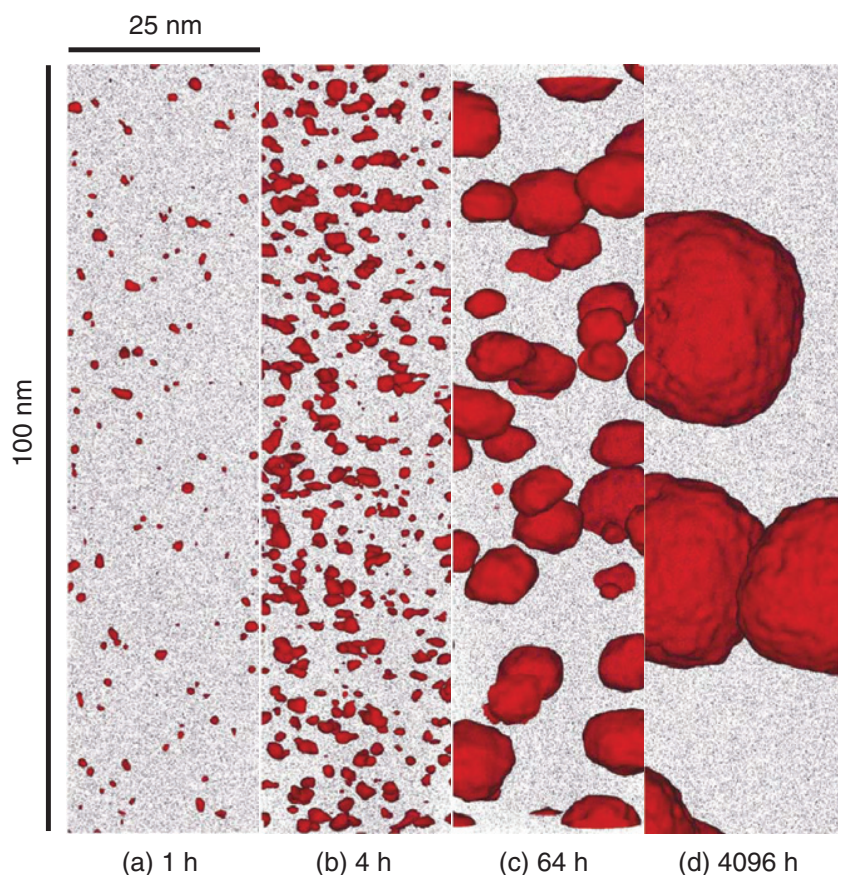

Figure 2. APT reconstructed 3D images of a Ni-6.5 Al-9.5 Cr at. \% alloy aged at $873 \mathrm{~K}$ for (a) $1 \mathrm{~h}$, (b) $4 \mathrm{~h}$, (c) $64 \mathrm{~h}$ and (d) $4096 \mathrm{~h}$. The nanometer-sized $\gamma^{\prime}$-precipitates are delineated with red $\mathrm{Al}$ isoconcentration surfaces. Al, which partitions to the $\gamma^{\prime}$-precipitates, is shown in red, whereas $\mathrm{Cr}$, which partitions to the $\gamma$-matrix, is shown in blue; $\mathrm{Ni}$ atoms are omitted for clarity. 
from 0.5 to $1.5 \mathrm{~h}$; followed by (ii) concomitant precipitate nucleation, growth and coagulation and coalescence from 1.5 to $4 \mathrm{~h}$; (iii) concurrent growth and coarsening between 4 and $256 \mathrm{~h}$; and finally (iv) quasi-stationary state coarsening of $\gamma^{\prime}$-precipitates from 256 to $4096 \mathrm{~h}$. Figure 3 displays the temporal evolution of the $\gamma^{\prime}$-precipitate volume fraction, $\phi$, average radius, $\langle R(t)\rangle$, and number density, $N_{v}(t)$, and clearly shows these four stages of phase decomposition in this model alloy. The $\gamma^{\prime}$-precipitate nanostructural properties determined by APT analysis are summarized in Table 1.

Phase separation by nucleation has been studied theoretically for binary alloys in a set of models known as classical nucleation theory (CNT), which have been reviewed extensively in the literature [35-40]. According to CNT, nucleation is governed by a balance between a bulk free energy term, which has both chemical, $\Delta F_{c h}$, and elastic strain energy, $\Delta F_{e l}$, components, and an interfacial free energy term, $\sigma^{\gamma / \gamma^{\prime}}$; where $F$ is the Helmholtz free energy. Experimental validation of CNT is quite difficult for solid solutions, due to the short time and length scales involved

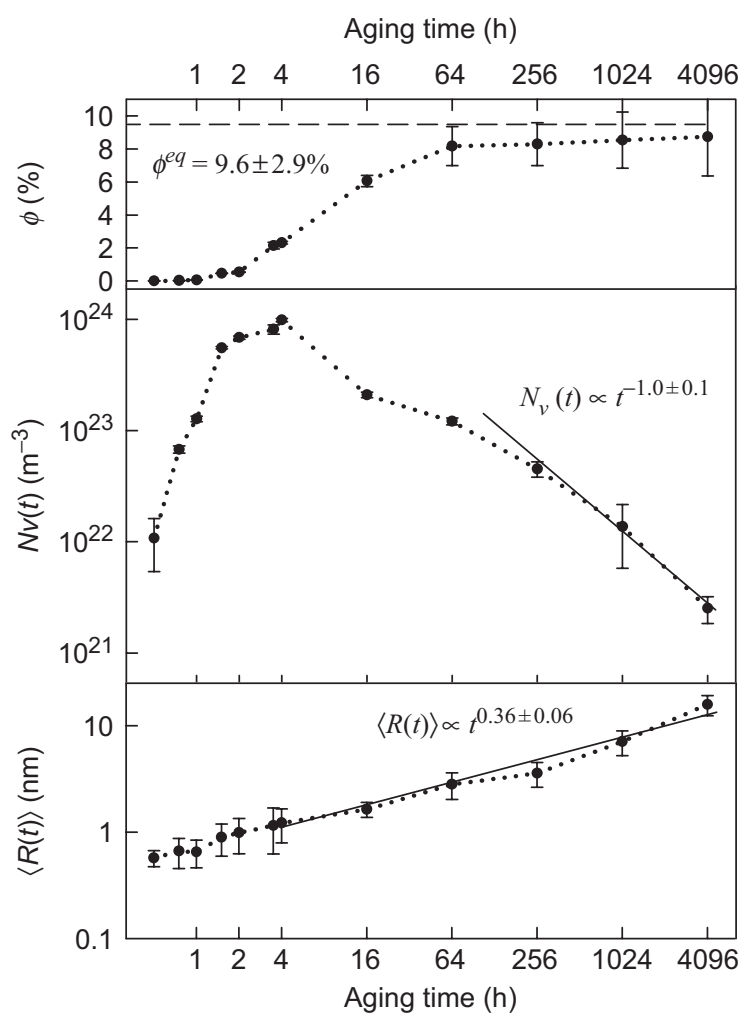

Figure 3. The temporal evolution of the $\gamma^{\prime}$-precipitate volume fraction, $\phi$, number density, $N_{v}(t)$, and mean radius, $\langle R(t)\rangle$, for $\mathrm{Ni}-6.5 \mathrm{Al}-9.5 \mathrm{Cr}$ at. $\%$ at $873 \mathrm{~K}$. The quantity $\langle R(t)\rangle$ is approximately proportional to $t^{1 / 3}$ during quasi-stationary state coarsening for aging times of $4 \mathrm{~h}$ and longer, as predicted by classical coarsening models. Once the equilibrium volume fraction is approximately achieved after $256 \mathrm{~h}$, the temporal dependence of the quantity $N_{v}(t)$ achieves the $t^{-1}$ prediction of the coarsening models. 
Table 1. Temporal evolution of the nanostructural properties of $\gamma^{\prime}$-precipitates determined by APT for Ni-6.5 Al-9.5 $\mathrm{Cr}$ at. $\%$ aged at $873 \mathrm{~K}$. The $\gamma^{\prime}$-precipitate mean radius, $\langle R(t)\rangle$, number density, $N_{v}(t)$, and volume fraction, $\phi$, are given, along with their standard errors.

\begin{tabular}{lcccc}
\hline Aging time $(\mathrm{h})$ & $N_{\mathrm{ppt}}{ }^{\mathrm{a}}$ & $\langle R(t)\rangle \pm 2 \sigma(\mathrm{nm})$ & $N_{v}(t) \pm 2 \sigma\left(\times 10^{23} \mathrm{~m}^{-3}\right)$ & $\phi \pm 2 \sigma(\%)$ \\
\hline 0.5 & 4 & $0.57 \pm 0.10$ & $0.11 \pm 0.05$ & $0.002 \pm 0.001$ \\
0.75 & 175 & $0.67 \pm 0.21$ & $0.68 \pm 0.05$ & $0.02 \pm 0$ \\
1 & 328 & $0.65 \pm 0.19$ & $1.27 \pm 0.07$ & $0.05 \pm 0$ \\
1.5 & 1599 & $0.90 \pm 0.30$ & $5.53 \pm 0.14$ & $0.46 \pm 0.01$ \\
2 & 755.5 & $0.99 \pm 0.36$ & $6.84 \pm 0.25$ & $0.54 \pm 0.02$ \\
3.5 & 109.5 & $1.16 \pm 0.53$ & $8.13 \pm 0.78$ & $2.14 \pm 0.20$ \\
4 & 905 & $1.23 \pm 0.43$ & $9.84 \pm 0.33$ & $2.32 \pm 0.08$ \\
16 & 314.5 & $1.64 \pm 0.26$ & $2.09 \pm 0.12$ & $6.06 \pm 0.34$ \\
64 & 47.5 & $2.82 \pm 0.79$ & $1.21 \pm 0.08$ & $8.17 \pm 1.19$ \\
256 & 40.5 & $3.58 \pm 0.93$ & $0.45 \pm 0.07$ & $8.29 \pm 1.30$ \\
1024 & 25 & $7.10 \pm 1.86$ & $0.14 \pm 0.08$ & $8.53 \pm 1.71$ \\
4096 & 13.5 & $15.80 \pm 3.39$ & $0.03 \pm 0.01$ & $8.74 \pm 2.38$ \\
\hline
\end{tabular}

Notes: ${ }^{a}$ The number of $\gamma^{\prime}$-precipitates analyzed, $N_{\mathrm{ppt}}$, is smaller than the total number of $\gamma^{\prime}$-precipitates detected by APT. Precipitates that intersect the sample volume contribute 0.5 to the quantity $N_{\mathrm{ppt}}$, and are included in the estimates of $N_{v}(t)$ and $\phi$, and the phase compositions, and not in the measurement of $\langle R(t)\rangle$.

in precipitation of second phases, which typically contain less than 100 atoms $[38,41]$. Control of the quenching conditions is important to minimize the vacancy concentration, while simultaneously insuring that phase decomposition does not occur during the quench. Additionally, the quantities involved in CNT, such as the interfacial energy, the thermodynamic driving force, and the solute diffusion coefficient, are difficult to measure, and the predictions of the models are highly sensitive to uncertainties in these values. As a result, the discrepancies between the measured and predicted nucleation rates are typically between three and five orders of magnitude [38,42].

From CNT, the expression for the net reversible work required for the formation of a spherical nucleus, $W_{R}$, as a function of nucleus radius, $R$, is given by

$$
W_{R}=\left(\Delta F_{c h}+\Delta F_{e l}\right) \frac{4 \pi}{3} R^{3}+4 \pi R^{2} \sigma^{\gamma / \gamma^{\prime}} .
$$

The critical net reversible work, $W_{R}^{*}$, required for the formation of a critical spherical nucleus is given by

$$
W_{R}^{*}=\frac{16 \pi}{3} \frac{\sigma^{\gamma / \gamma^{\prime}}}{\left(\Delta F_{c h}+\Delta F_{e l}\right)^{2}} .
$$

The critical net reversible work for nucleation acts as a barrier that nuclei must overcome to achieve a critical nucleus radius, $R^{*}$, given by

$$
R^{*}=\frac{2 \sigma^{\gamma / \gamma^{\prime}}}{-\left(\Delta F_{c h}+\Delta F_{e l}\right)} .
$$


From CNT, the stationary-state nucleation current, $J^{s t}$, the number of nuclei formed per unit volume per unit time $\left(\mathrm{m}^{-3} \mathrm{~s}^{-1}\right)$, is given by

$$
J^{s t}=Z \beta^{*} N \exp \left(\frac{-W_{R}^{*}}{k_{B} T}\right),
$$

where $Z$, the Zeldovich factor, accounts for the dissolution of supercritical clusters, $\beta^{*}$ is a kinetic coefficient describing the rate of condensation of single atoms on the critical nuclei, $N$ is the total number of possible nucleation sites per unit volume, taken to be the volume density of lattice sites occupied by $\mathrm{Al}$, the precipitating solute element [35,43], $k_{B}$ is Boltzmann's constant and $T$ is the absolute temperature. The standard definitions of $Z$ and $\beta^{*}$ were employed and are given by [35-40]

$$
\begin{gathered}
Z=\left[-\left(\frac{\partial^{2} W_{i}\left(i^{*}\right)}{\partial i^{2}}\right)\left(\frac{1}{2 \pi k_{B} T}\right)\right]^{1 / 2}, \\
\beta^{*}=\frac{4 \pi R^{*} D C_{0}}{a^{4}},
\end{gathered}
$$

where $W_{i}$ is the net reversible work required for the formation of a spherical nucleus containing $i$ atoms, $D$ is the diffusion coefficient of the precipitating solute element, $C_{0}$ is the initial concentration of said solute and $a$ is the average of the lattice parameters of the matrix and precipitate phase, equal, in this case, to $0.3568 \mathrm{~nm}$. Given that the extant theories of nucleation are for binary alloys, the calculations of the stationary-state nucleation rate were performed for both $\mathrm{Al}$ and $\mathrm{Cr}$, thereby providing an upper and lower bound for the predicted nucleation rate. Diffusion coefficients of 9.47 and $2.61 \times 10^{-21} \mathrm{~m}^{2} \mathrm{~s}^{-1}$ were employed for $\mathrm{Al}$ and $\mathrm{Cr}$, respectively, along with $C_{0}$ values of 6.5 and 9.5 at. $\%$.

The value of $\Delta F_{c h}$ of $-6.25 \times 10^{7} \mathrm{~J} \mathrm{~m}^{-3}$ is determined from Thermo-Calc [25] and the Saunders thermodynamic database [44], and is calculated employing the equilibrium phase compositions, an assumption which is valid for this alloy, given the small values of the solute supersaturations [38,45-47]. The values of $\Delta F_{e l}$, the elastic energy, for the two alloys are estimated using [48]

$$
\Delta F_{e l}=\frac{2 S^{\gamma} B^{\gamma^{\prime}}\left(V_{a}^{\gamma^{\prime}}-V_{a}^{\gamma}\right)^{2}}{\left(3 B^{\gamma^{\prime}}+4 S^{\gamma}\right) V_{a}^{\gamma^{\prime}}},
$$

where $S^{\gamma}$ is the shear modulus of the $\gamma$-matrix phase, $B^{\gamma^{\prime}}$ is the bulk modulus of the $\gamma^{\prime}$-precipitate phase, and $V_{a}^{\gamma}$ and $V_{a}^{\prime \prime}$ are the atomic volumes of the $\gamma$-matrix and $\gamma^{\prime}$-precipitate phases, respectively. No elastic constants are available for this alloy; therefore the value of $S^{\gamma}$ of $100.9 \mathrm{GPa}$, of a similar alloy, $\mathrm{Ni}-12.69 \mathrm{Al}$ at $873 \mathrm{~K}$ [49] is employed, whereas the value of $B^{\gamma^{\prime}}$ is taken to be $175 \mathrm{GPa}$ [50]. The lattice parameters of the $\gamma^{\prime}$ - and $\gamma$-phases at $873 \mathrm{~K}$ are calculated to be $0.3573 \mathrm{~nm}$ and $0.3563 \mathrm{~nm}$, respectively, employing the precipitation simulation software program PrecipiCalc [51,52]. These lattice parameter values result in a near-zero value of the lattice parameter misfit of 0.00284 for $\mathrm{Ni}-6.5 \mathrm{Al}-9.5 \mathrm{Cr}$ at. \%. Substituting these values into Equation (7) yields a value of $\Delta F_{e l}$ of $2.67 \times 10^{6} \mathrm{~J} \mathrm{~m}^{-3}$. The high degree of coherency of the $\gamma^{\prime}$-precipitates in this alloy is such that the bulk component of the 
driving force for nucleation is dominated by the $\Delta F_{c h}$ term, as $\Delta F_{e l}$ is only $4.27 \%$ of the value of $\Delta F_{c h}$. A value of $\sigma^{\gamma / \gamma^{\prime}}$ of $22 \pm 1 \mathrm{~mJ} \mathrm{~m}^{-2}$ is estimated by a technique that relies on thermodynamic information and experimental coarsening data, and was first used by Ardell for a binary alloy [44,53], and extended to the ternary $\mathrm{Al}-\mathrm{Sc}-\mathrm{Mg}$ and $\mathrm{Ni}-\mathrm{Al}-\mathrm{Cr}$ alloys [3,4,54], and is described in detail therein. The value of $\sigma^{\gamma / \gamma^{\prime}}$ of $22 \pm 1 \mathrm{~mJ} \mathrm{~m}^{-2}$ estimated for $\mathrm{Ni}-6.5 \mathrm{Al}-9.5 \mathrm{Cr}$ at. $\%$ is in excellent agreement with the values of $20-25 \mathrm{~mJ} \mathrm{~m}^{-2}$ determined by the same technique for $\mathrm{Ni}-\mathrm{Al}-\mathrm{Cr}$ alloys aged at $873 \mathrm{~K}$ [3]. We note that the value of $\sigma^{\gamma / \gamma^{\prime}}$ during nucleation may differ significantly from this value, since the latter was obtained from the coarsening regime, after the $\gamma^{\prime}$-precipitates have undergone a significant amount of temporal evolution. Unfortunately, there is no extant technique to estimate the value of $\sigma^{\gamma / \gamma^{\prime}}$ during nucleation for this ternary alloy aged at $873 \mathrm{~K}$.

Employing the values of $\Delta F_{c h}, \Delta F_{e l}$, and $\sigma^{\gamma / \gamma^{\prime}}$ given above, CNT predicts nucleation currents of $1.06 \times 10^{23}$ and $6.24 \times 10^{22} \mathrm{~m}^{-3} \mathrm{~s}^{-1}$, employing the diffusion data for $\mathrm{Al}$ and $\mathrm{Cr}$, respectively. These values are 700 and 285 times greater, respectively, than the measured rate of $1.5 \pm 0.7 \times 10^{20} \mathrm{~m}^{-3} \mathrm{~s}^{-1}$. Given the evidence of precursor clustering in these $\mathrm{Ni}-\mathrm{Al}-\mathrm{Cr}$ alloys [10], it is surprising that the experimentally determined value of $J^{s t}$ is significantly less than the predicted value. Predictions of the nucleation rate by CNT have been found to be 50-500 times greater than the experimental values for other $\mathrm{Ni}-\mathrm{Al}$ and $\mathrm{Ni}-\mathrm{Al}-\mathrm{Cr}$ alloys $[3,55]$. Xiao and Haasen attributed this discrepancy to the sensitivity of the predicted value of $J^{\text {st }}$ to the value of $R^{*}$ [55]. They also noted that predicted nucleation currents are likely overestimated due to the assumption that the value of $N_{0}$ is equal to the volume density of lattice sites, which is a commonly made assumption that is not necessarily correct. By assuming that the value of $N_{0}$ is equal to the volume density of $\mathrm{Al}$ atoms, we have mitigated this error to some extent. The prediction of $R^{*}$ from CNT, which depends only on thermodynamic quantities, yields a value of $0.74 \mathrm{~nm}$, in agreement with the value of $\langle R(t)\rangle$ of $0.62 \pm 0.17$ we measured for aging times of $0.5-1 \mathrm{~h}$.

To date, there is not a generally accepted theory of nucleation in concentrated multicomponent alloys. Given that the detailed atomistic kinetics involved in the formation of $\gamma^{\prime}$-nuclei in these ternary systems are not completely understood, further analysis herein is not instructive. The earliest stages of precipitate formation in $\mathrm{Ni}-6.5 \mathrm{Al}-9.5 \mathrm{Cr}$ at. \% are described in greater detail elsewhere [56], and complemented with results of lattice kinetic Monte Carlo simulation to develop a deeper understanding of the kinetic pathways of nucleation in this alloy.

Nucleation and growth of $\gamma^{\prime}$-precipitates occurs concurrently for aging times of 1.5 to $4 \mathrm{~h}$, resulting in a nucleation current of $4.1 \pm 1.6 \times 10^{19} \mathrm{~m}^{-3} \mathrm{~s}^{-1}$, and an increase in the value of $\phi$ from $0.46 \pm 0.01 \%$ to $2.32 \pm 0.08 \%$. As such, we do not observe a pure growth regime [57-59], which is not surprising given the evidence of concomitant $\gamma^{\prime}$-precipitate nucleation, growth and coagulation and coalescence between 1.5 and $4 \mathrm{~h}$.

For aging times between 4 and $256 \mathrm{~h}$, the values of $\phi$ and $\langle R(t)\rangle$ increase, and the values of $N_{v}(t)$ decrease, as expected for quasi-stationary-state coarsening. Previous investigations of the phase separation of $\mathrm{Ni}-\mathrm{Al}-\mathrm{Cr}$ alloys have shown that the predictions of the temporal evolution of the quantity $\langle R(t)\rangle$ from classical coarsening models are validated experimentally during quasi-stationary-state coarsening [3-10]. 
The predicted temporal evolutions of the quantity $N_{v}(t)$ and of the particle size distributions have not been validated experimentally. This is because experimental alloys have failed to achieve genuine stationary-state coarsening at the equilibrium volume fraction of the precipitated phase [60-63]. The first comprehensive meanfield treatment of coarsening, due to Lifshitz and Slyozov [64] and Wagner [65], known as the LSW model, is limited to dilute binary alloys with spatially-fixed spherical precipitates whose initial compositions are equal to their equilibrium values, as determined by the equilibrium binary phase diagram. These stringent requirements, and other assumptions inherent to the LSW model, are highly restrictive, and difficult to meet in practice. Researchers have worked to remove the mean-field restrictions by developing models based on multiparticle diffusion that are able to describe stress-free systems with finite volume fractions [62,66-68]. Umantsev and Olson (UO) [69] demonstrated that the exponents of the temporal power-laws for concentrated multi-component alloys are identical with those for dilute binary alloys, but that the explicit expressions for the rate constants depend on the number of components. Kuehmann and Voorhees (KV) [70] considered isothermal coarsening in ternary alloys and developed a detailed model that includes the effects of capillarity on the precipitate composition, such that the phase compositions can deviate from their equilibrium values. In the quasi-stationary-state limit of the KV model, the expressions for the temporal dependencies for $\langle R(t)\rangle$, $N_{v}(t)$, and the $\gamma$-matrix supersaturation, $\Delta C_{i}^{\gamma}(t)$, of each solute species $i$, are

$$
\begin{gathered}
\langle R(t)\rangle^{3}-\left\langle R\left(t_{0}\right)\right\rangle^{3}=K_{K V}\left(t-t_{0}\right), \\
N_{v}(t)^{-1} \cong \frac{4.74 K_{K V}}{\phi^{e q}} t,
\end{gathered}
$$

and

$$
\Delta C_{i}^{\gamma}(t)=\left\langle C_{i}^{\gamma, f f}(t)\right\rangle-C_{i}^{\gamma, e q}(\infty)=\kappa_{i, K V}^{\gamma} t^{-1 / 3},
$$

where $K_{K V}$, and $\kappa_{i, K V}^{\gamma}$ are the coarsening rate constants for $\langle R(t)\rangle$ and $\Delta C_{i}^{\gamma}(t)$, respectively; $\left\langle R\left(t_{0}\right)\right\rangle$ is the average precipitate radius and $N_{v}\left(t_{0}\right)$ is the precipitate number density at the onset of quasi-stationary-state coarsening, at time $t_{0}$. The quantity $\Delta C_{i}^{\gamma}(t)$ is denoted a supersaturation and is the difference between the concentration in the far-field $\gamma$-matrix, $\left\langle C_{i}^{\gamma, f f}(t)\right\rangle$, and the equilibrium $\gamma$-matrix solute-solubility, $C_{i}^{\gamma, e q}(\infty)$. The temporal dependence of the quantity $\langle R(t)\rangle$ for the alloy studied herein is measured to be $t^{0.36 \pm 0.06}$ from the onset of coarsening at $4 \mathrm{~h}$ to $4096 \mathrm{~h}$. As noted previously, the prediction of the temporal evolution of the quantity $\langle R(t)\rangle$ has been validated for systems where the equilibrium volume fraction has not been achieved, as is the case for $\mathrm{Ni}-6.5 \mathrm{Al}-9.5 \mathrm{Cr}$ at. \% for aging times of 4-256 $\mathrm{h}$. Thus, its measurement alone is not a particularly strong test of the LSW model.

During aging from 4 to $16 \mathrm{~h}$, the value of $N_{v}(t)$ drops sharply from the maximum value of $9.84 \pm 0.33 \times 10^{23} \mathrm{~m}^{-3}$ at $4 \mathrm{~h}$, to $2.09 \pm 0.12 \times 10^{23} \mathrm{~m}^{-3}$ at $16 \mathrm{~h}$ as a result of coarsening via both the classical evaporation-condensation mechanism and the coagulation and coalescence of $\gamma^{\prime}$-precipitates. The fraction of coagulating and coalescing $\gamma^{\prime}$-precipitates is $25 \pm 3 \%$ after $4 \mathrm{~h}$ of aging, and $12 \pm 2 \%$ after $16 \mathrm{~h}$ of aging; thus coarsening via this mechanism is significant at these times. Note that the 
value of $\phi$ increases from $2.31 \pm 0.08$ to $6.06 \pm 0.34 \%$ over this range of time, thus $\gamma^{\prime}$-precipitate growth is also ongoing. After aging for $64 \mathrm{~h}$, only $4 \pm 1 \%$ of $\gamma^{\prime}$-precipitates are undergoing coagulation and coalescence, and therefore coarsening proceeds primarily via the evaporation-condensation mechanism. For aging times of 256 to $4096 \mathrm{~h}$, where no coagulation and coalescence of $\gamma^{\prime}$-precipitates is detected, and the volume fraction of $\gamma^{\prime}$-precipitates is approximately constant, the temporal dependence of the quantity $N_{v}(t)$ is $t^{-1.0 \pm 0.1}$, as predicted by extant models of coarsening, including the detailed KV model for ternary alloys [64,65,70-72].

\subsection{Temporal evolution of the compositions of the $\gamma$ and $\gamma^{\prime}$ phase compositions}

The compositions of the $\gamma$-matrix and $\gamma^{\prime}$-precipitate phases in $\mathrm{Ni}-6.5 \mathrm{Al}-9.5 \mathrm{Cr}$ at. $\%$ evolve temporally, as the $\gamma$-matrix is enriched in $\mathrm{Ni}$ and $\mathrm{Cr}$ and depleted of $\mathrm{Al}$, as shown in Figure 4. The first $\gamma^{\prime}$-nuclei, detected at an aging time of $0.5 \mathrm{~h}$, have a solute supersaturated composition of $70.1 \pm 3.0 \mathrm{Ni}, 21.3 \pm 4.9 \mathrm{Al}$ and $8.7 \pm 5.3 \mathrm{Cr}$ at. $\%$, with a value of $\langle R(t=0.5 \mathrm{~h})\rangle$ of $0.57 \pm 0.10 \mathrm{~nm}$. As phase separation proceeds, the values of $\Delta C_{i}^{\gamma}(t)$ and the $\gamma^{\prime}$-precipitate supersaturation, $\Delta C_{i}^{\gamma^{\prime}}(t)$, decrease asymptotically as the $\gamma$-and $\gamma^{\prime}$-phase compositions approach their equilibrium values. The equilibrium compositions of the $\gamma$-matrix and $\gamma^{\prime}$-precipitate phases are determined

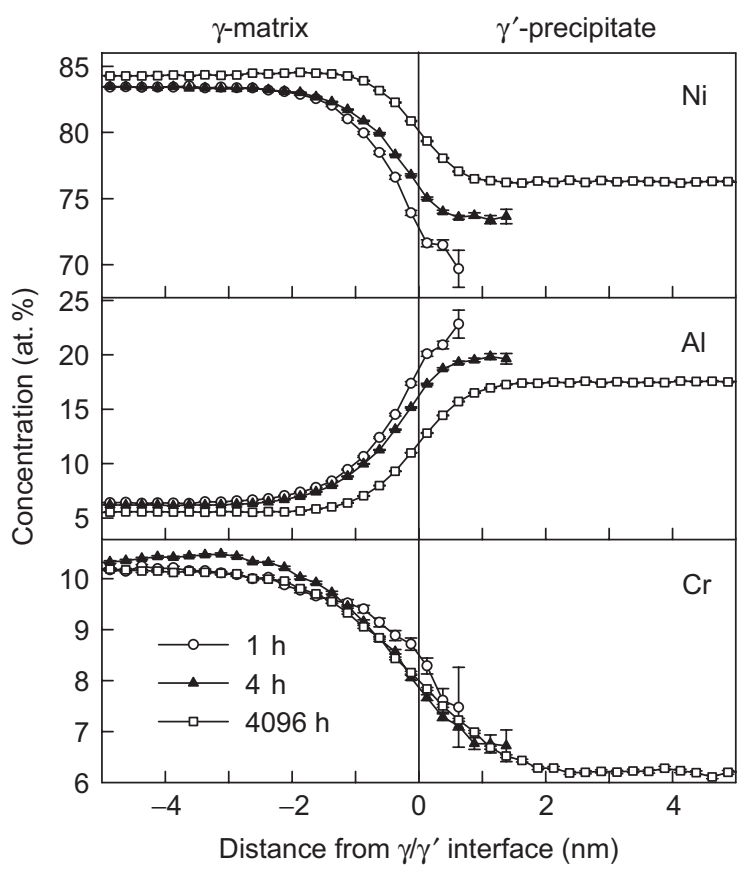

Figure 4. The composition profiles across the $\gamma$-matrix $/ \gamma^{\prime}$-precipitate interface for Ni-6.5 Al- $9.5 \mathrm{Cr}$ at. $\%$ at $873 \mathrm{~K}$ for aging times of 1,4 and $4096 \mathrm{~h}$. The phase compositions evolve temporally, as the $\gamma$-matrix becomes enriched in $\mathrm{Ni}$ and $\mathrm{Cr}$ and depleted in $\mathrm{Al}$. The values of $\langle R(t)\rangle$ for these aging times are $0.65 \pm 0.19 \mathrm{~nm}$ for $1 \mathrm{~h}, 1.23 \pm 0.43 \mathrm{~nm}$ for $4 \mathrm{~h}$ and $15.80 \pm 3.39 \mathrm{~nm}$ for $4096 \mathrm{~h}$. 
from Equation (10) to be $84.19 \pm 0.02 \mathrm{Ni}-5.49 \pm 0.05 \mathrm{Al}-10.30 \pm 0.05 \mathrm{Cr}$ and $76.40 \pm 0.19 \mathrm{Ni}-17.53 \pm 0.33 \mathrm{Al}-6.06 \pm 0.36 \mathrm{Cr}$ at. \%, respectively. These values are used to estimate an equilibrium volume fraction of $\gamma^{\prime}$-precipitates, $\phi^{e q}$, of $9.6 \pm 2.9 \%$, according to the lever rule. The values of $\phi$ of $8.29 \pm 1.30,8.53 \pm 1.71$ and $8.74 \pm 2.38 \%$ determined by APT for aging times of 256, 1024 and $4096 \mathrm{~h}$, respectively, are all within the experimental error of the $\phi^{e q}$ value of $9.6 \pm 2.9 \%$. Thus, by an aging time of $256 \mathrm{~h}$, growth of $\gamma^{\prime}$-precipitates is complete, and phase decomposition proceeds only by quasi-stationary-state coarsening.

The temporal evolution of the phase compositions is shown on a partial ternary $\mathrm{Ni}-\mathrm{Al}-\mathrm{Cr}$ phase diagram determined by the GCMC technique at $873 \mathrm{~K}$ (Figure 5) [14]. For comparative purposes, the compositional trajectories of $\mathrm{Ni}-7.5 \mathrm{Al}-8.5 \mathrm{Cr}$ and $\mathrm{Ni}-5.2 \mathrm{Al}-14.2 \mathrm{Cr}$ at. \%, two alloys that have also been investigated by APT at Northwestern University, are superimposed on the phase diagram. According to the $\mathrm{KV}$ coarsening model, the addition of a third alloying element alters both the form of the Gibbs-Thompson equations and the predictions of the temporal evolution of the phase compositions [70]. The slope of the trajectory of the $\gamma$-matrix phase during coarsening is predicted by the $\mathrm{KV}$ model to lie along the equilibrium tie-line and have a value of $p_{\mathrm{Al}} / p_{\mathrm{Cr}}$, where $p_{i}$ is the magnitude of the partitioning of solute species $i$, as defined by the expression $p_{i}=\left[C_{i}^{\gamma^{\prime}}, e q(\infty)-C_{i}^{\gamma, e q}(\infty)\right]$. Alternatively, the compositional trajectory of the $\gamma^{\prime}$-precipitate phase is predicted by the $\mathrm{KV}$ model

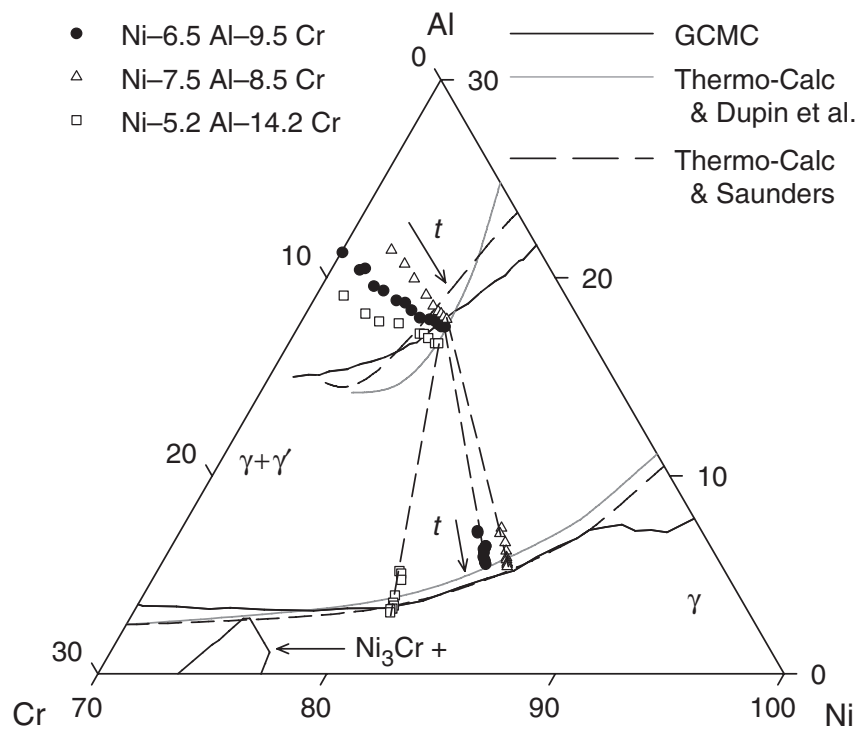

Figure 5. The compositional trajectories of the $\gamma$-matrix and $\gamma^{\prime}$-precipitate phases of Ni-6.5 $\mathrm{Al}-9.5 \mathrm{Cr}$ at. $\%$, displayed on a partial $\mathrm{Ni}-\mathrm{Al}-\mathrm{Cr}$ ternary phase diagram at $873 \mathrm{~K}$. The trajectory of the $\gamma$-matrix phase lies approximately on the experimental tie-line, while the trajectory of the $\gamma^{\prime}$-precipitate phases does not lie along the tie-line, as predicted by the Kuehmann-Voorhees coarsening model [70]. The tie-lines are determined from the equilibrium phase compositions, determined by extrapolation of APT concentration data to infinite time, which is a small extrapolation of the compositions. 


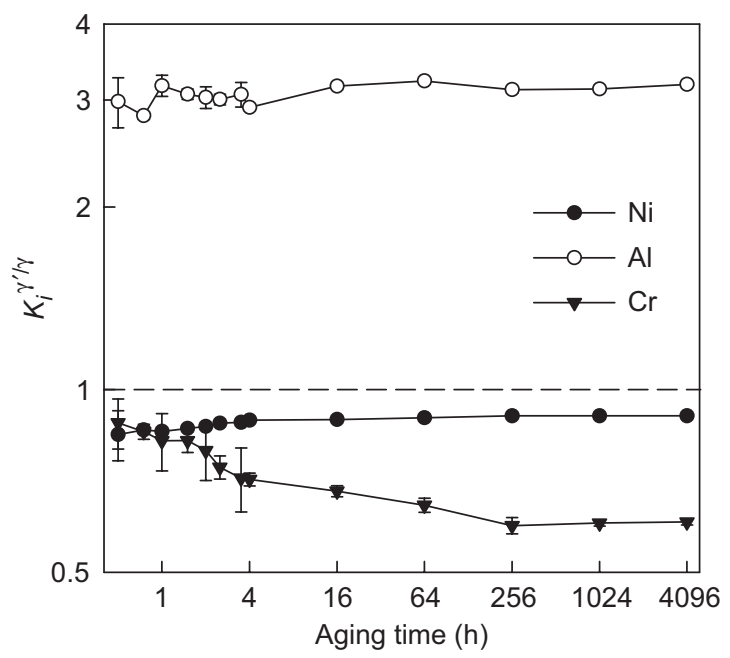

Figure 6. The partitioning ratios, $K_{i}^{\gamma / \gamma^{\prime}}$, quantify the partitioning of $\mathrm{Al}$ to the $\gamma^{\prime}$-precipitates and of $\mathrm{Ni}$ and $\mathrm{Cr}$ to the $\gamma$-matrix. The values of $K_{i}^{\gamma / \gamma \prime}$ are constant from 256 to $4096 \mathrm{~h}$, when the alloy is undergoing quasi-stationary state coarsening.

to lie on a straight line that is not necessarily parallel to the equilibrium tie-line. To verify these predictions for the ternary alloy studied, the quantities $\delta C_{\mathrm{Al}}^{\gamma}(t) / \delta C_{\mathrm{Cr}}^{\gamma}(t)$ and $\delta C_{\mathrm{Al}}^{\gamma^{\prime}}(t) / \delta C_{\mathrm{Cr}}^{\gamma^{\prime}}(t)$ for aging times of 4-4094 $\mathrm{h}$ are compared to the value of $p_{\mathrm{Al}} / p_{\mathrm{Cr}}$, where $\delta C^{p}{ }_{i}$ is the slope of the concentration of element $i$ in phase $p$ with aging time. The trajectories of the $\gamma$-matrix phase and the $\gamma^{\prime}$-precipitate phases have slopes of $-4.29 \pm 0.52$ and $0.56 \pm 0.24$, respectively, whereas the slope of the equilibrium tie-line is estimated to be $-2.84 \pm 0.06$. From these results, it is absolutely clear that the trajectory of the $\gamma^{\prime}$-precipitate composition does not lie along the equilibrium tie line. This result is contrary to all coarsening models, except the $\mathrm{KV}$ model for ternary alloys. We note that the KV mean-field model is unable to predict the correct values of the slopes, which is most likely due to the omission of the off-diagonal terms in the diffusion matrix in this model. The omission of the off-diagonal terms, in turn, generates inaccurate predictions of the diffusion fluxes into and out of the $\gamma^{\prime}$-precipitate phase by suppressing flux coupling [34].

The values plotted on the phase diagram in Figure 5 are the far-field plateau compositions of the two phases, and do not include atoms that lie within the interfacial $\gamma / \gamma^{\prime}$ region. As such, the rule of mixtures, which dictates that the nominal $\gamma^{\prime}$-precipitate and $\gamma$-matrix compositions at a given aging time lie along a straight line, is not satisfied. Classical models of phase separation often ignore the interfacial region, thus we have chosen a similar approach for comparative purposes. The inclusion of the interfacial region in the phase compositions (not displayed) does not alter the compositional trajectories significantly, and does satisfy the rule of mixtures. Advanced models of phase separation are needed to account for the interfacial region between phases. The interfacial region, which has a definite width on the order of $\sim 2 \mathrm{~nm}$ for this alloy (Figure 4 ) has been measured to be on the order of several nanometers for other model nickel-based superalloys [3,4,14,73-77]. 

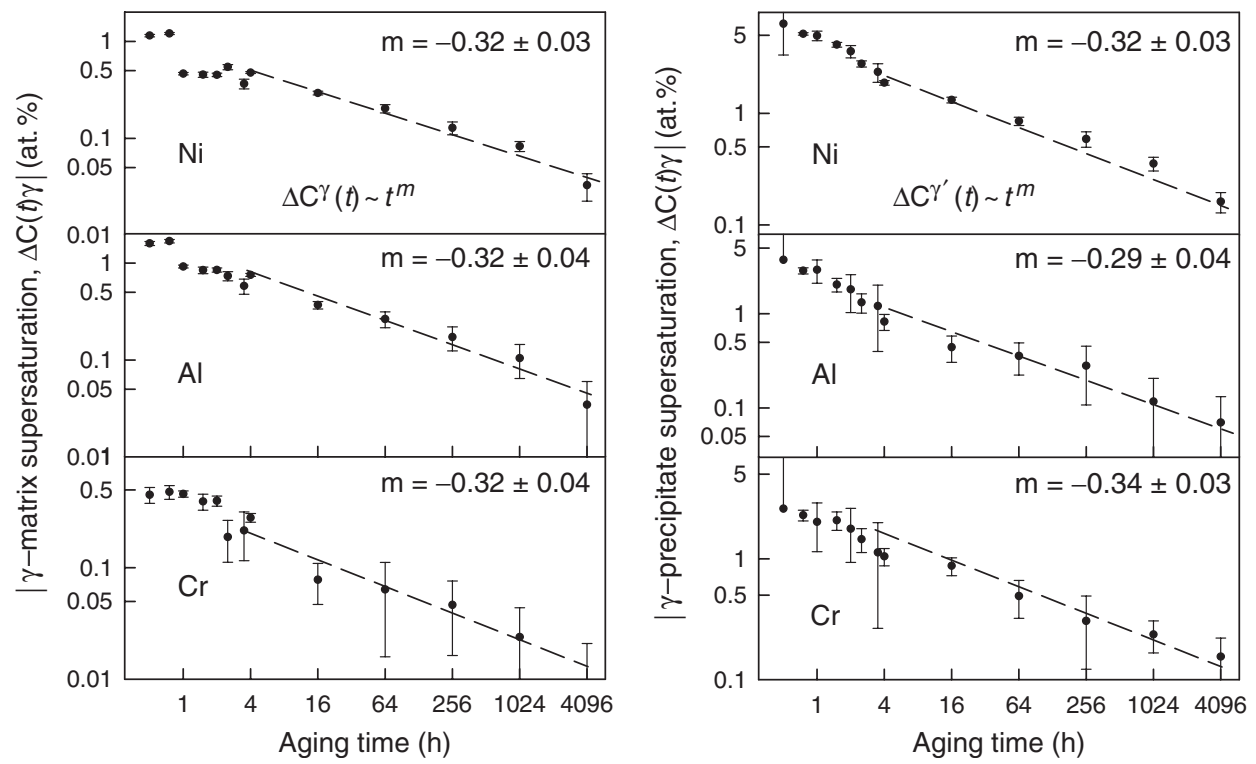

Figure 7. The magnitude of the values of the $\gamma$-matrix (left) and $\gamma^{\prime}$-precipitate (right) supersaturations, $\Delta C_{i}^{\gamma}(t)$ and $\Delta C_{i}^{\gamma^{\prime}}(t)$, of $\mathrm{Ni}, \mathrm{Al}$ and $\mathrm{Cr}$, decrease as approximately $t^{-1 / 3}$ in the coarsening regime, as predicted by classical coarsening models.

The partitioning behavior of the elements can be determined quantitatively by calculating the partitioning ratio, $K_{i}^{\gamma / \gamma^{\prime}}$, defined as the ratio of the concentration of an element $i$ in the $\gamma^{\prime}$-precipitates to the concentration of the same element in the $\gamma$-matrix. Figure 6 demonstrates partitioning of Al to the $\gamma^{\prime}$-precipitates and of $\mathrm{Ni}$ and $\mathrm{Cr}$ to the $\gamma$-matrix. The values of $K_{i}^{\gamma / \gamma^{\prime}}$ are constant from 256 to $4096 \mathrm{~h}$, when the alloy is undergoing quasi-stationary state coarsening.

The diminution of the $\gamma$-matrix supersaturation values approximately follows the $t^{-1 / 3}$ prediction of the KV model. From Figure 7, the alloy displays a temporal dependence of $t^{-0.32 \pm 0.03}$ for $\Delta C_{\mathrm{Ni}}^{\gamma}(t), t^{-0.32 \pm 0.04}$ for $\Delta C_{\mathrm{Al}}^{\gamma}(t)$ and $t^{-0.32 \pm 0.04}$ for $\Delta C_{\mathrm{Cr}}^{\gamma}(t)$. The temporal dependencies of the $\gamma^{\prime}$-precipitate supersaturation values also follow approximately the $t^{-1 / 3}$ prediction, with measured dependencies of $t^{-0.32 \pm 0.03}$ for $\Delta C_{\mathrm{N} i}^{\gamma^{\prime}}(t), t^{-0.29 \pm 0.04}$ for $\Delta C_{\mathrm{Al}}^{\gamma^{\prime}}(t)$ and $t^{-0.34 \pm 0.03}$ for $\Delta C_{\mathrm{Cr}}^{\gamma^{\prime}}(t)$.

\section{Conclusions}

A detailed comparison was obtained of the nanostructural and compositional evolution of $\mathrm{Ni}-6.5 \mathrm{Al}-9.5 \mathrm{Cr}$ at. \% during phase separation at $873 \mathrm{~K}$ for aging times ranging from 0.5 to $4096 \mathrm{~h}$, employing atom-probe topography (APT). This ternary alloy with a low equilibrium $\gamma^{\prime}$-precipitate volume fraction of $9.6 \pm 2.9 \%$ was designed to study precipitate nucleation, and subsequently growth and coarsening, leading to the following results:

- The phase separation of the model alloy occurs in four distinct regimes: (i) quasi-stationary-state $\gamma^{\prime}$-precipitate nucleation from 0.5 to $1.5 \mathrm{~h}$; 
(ii) followed by concomitant precipitate nucleation, growth and coagulation and coalescence from 1.5 to $4 \mathrm{~h}$; (iii) concurrent growth and coarsening from 4 to $256 \mathrm{~h}$, wherein coarsening occurs via both $\gamma^{\prime}$-precipitate coagulation and coalescence and by the classical evaporation-condensation mechanism; and (iv) finally quasi-stationary-state coarsening of $\gamma^{\prime}$-precipitates from 256 to $4096 \mathrm{~h}$.

- The morphology of the $\gamma^{\prime}$-precipitate phase is found to be spheroidal for aging times as long as $1024 \mathrm{~h}$, as a result of a near-zero lattice parameter misfit between the $\gamma$-matrix and $\gamma^{\prime}$-precipitate phases. Coagulation and coalescence of $\gamma^{\prime}$-precipitates is observed for aging times of 1.5 to $64 \mathrm{~h}$, as a result of the overlap of the non-equilibrium concentration profiles associated with adjacent $\gamma^{\prime}$-precipitates [34]. The $\gamma^{\prime}$-precipitates that have formed by an aging time of $4096 \mathrm{~h}$ have commenced a spheroidalto-cuboidal morphological transformation to minimize their elastic strain energy as they increase in size [31-33].

- It is found that classical nucleation theory accurately predicts the critical radius for nucleation for the model $\mathrm{Ni}-\mathrm{Al}-\mathrm{Cr}$ alloy, although the prediction of the stationary-state nucleation current is at least 285 times greater than the value measured experimentally. These findings indicate that a better understanding of the kinetic pathways of nucleation in this concentrated ternary alloy is required. The time law predictions of the Umantsev-Olson [69] and Kuehmann-Voorhees [70] models of coarsening are verified experimentally for this model $\mathrm{Ni}-\mathrm{Al}-\mathrm{Cr}$ alloy. Beyond an aging time of $4 \mathrm{~h}$, the temporal evolutions of the values of the average precipitate radii and $\gamma$-matrix and $\gamma^{\prime}$-precipitate supersaturations follow the predictions of $t^{1 / 3}$ and $t^{-1 / 3}$, respectively. For aging times beyond $256 \mathrm{~h}$, the volume fraction of $\gamma^{\prime}$-precipitates is constant and the temporal dependence of the quantity $N_{v}(t)$ is $t^{-1.0 \pm 0.1}$.

- The solute solubility in the $\gamma$-matrix phase of $\mathrm{Ni}-6.5 \mathrm{Al}-9.5 \mathrm{Cr}$ at. $\%$ is determined by APT to be $5.49 \pm 0.05 \mathrm{Al}-10.30 \pm 0.05 \mathrm{Cr}$, whereas the equilibrium $\gamma^{\prime}$-precipitate composition is $76.40 \pm 0.19 \mathrm{Ni}-17.53 \pm 0.33$ $\mathrm{Al}-6.06 \pm 0.36 \mathrm{Cr}$ at. $\%$. These values are used to estimate an equilibrium volume fraction of $\gamma^{\prime}$-precipitates, $\phi^{e q}$, of $9.6 \pm 2.9 \%$, according to the lever rule. The values of $\phi$ of $8.29 \pm 1.30,8.53 \pm 1.71$ and $8.74 \pm 2.38 \%$ determined by APT for aging times of 256, 1024 and $4096 \mathrm{~h}$, respectively, are all within the experimental error of the $\phi^{e q}$ value of $9.6 \pm 2.9 \%$. Thus, by an aging time of $256 \mathrm{~h}$, growth of $\gamma^{\prime}$-precipitates is complete, and phase separation proceeds only by quasi-stationary-state coarsening.

- The compositional trajectory of the $\gamma$-matrix during phase separation lies approximately along the tie-line, while the trajectory of the $\gamma^{\prime}$-precipitate phase does not, as predicted by the KV mean-field model for quasistationary state coarsening in ternary alloys. The addition of a third alloying element alters the Gibbs-Thompson equations significantly, and as such, the $\mathrm{KV}$ model predicts that the compositional trajectory of the $\gamma^{\prime}$-precipitate phase will lie on a straight line that is not necessarily parallel to the equilibrium tie-line. The KV model, however, is unable to predict the exact value of the trajectones of the slopes, which is most likely due 
to the omission of the off-diagonal terms in the diffusion matrix in this model, which generates inaccurate predictions of the diffusion fluxes into and out of the $\gamma^{\prime}$-precipitate phase by suppressing flux coupling [34].

- An estimate of the $\gamma / \gamma^{\prime}$ interfacial free energy, $\sigma^{\gamma / \gamma^{\prime}}$, from the coarsening data obtained by APT yields a value of $22 \pm 1 \mathrm{~mJ} \mathrm{~m}^{-2}$. This value for $\mathrm{Ni}-6.5$ Al-9.5 Cr at. $\%$ is in excellent agreement with the values of $20-25 \mathrm{~mJ} \mathrm{~m}^{-2}$ measured by the same technique for other $\mathrm{Ni}-\mathrm{Al}-\mathrm{Cr}$ alloys aged at $873 \mathrm{~K}[3]$.

\section{Acknowledgements}

This research was sponsored by the National Science Foundation under grant DMR080461, Dr. H. Chopra, grant officer. APT measurements were performed at the Northwestern University Center for Atom Probe Tomography (NUCAPT). The LEAP tomograph was purchased and upgraded with funding from the NSF-MRI (DMR 0420532, Dr. C. Bouldin, grant officer) and ONR-DURIP (N00014-0400798 and N00014-0610539, Dr. J. Christodoulou, grant officer). We extend our gratitude to Dr. C. Campbell of the National Institute of Standards and Technology, Metallurgy Division, (Gaithersburg, MD) for diffusivity calculations and to Dr. D. Isheim for managing NUCAPT, and for discussions of our results. We thank Prof G. B. Olson and Dr. H.-J. Jou of QuesTek LLC (Evanston, IL) for use of PrecipiCalc.

\section{References}

[1] R.C. Reed, The Superalloys: Fundamentals and Applications, Cambridge University Press, New York, 2006.

[2] M. Durand-Charre, The Microstructure of Superalloys, Gordon and Breach Science, Amsterdam, 1997.

[3] C. Booth-Morrison, J. Weninger, C.K. Sudbrack, Z. Mao, R.D. Noebe and D.N. Seidman, Acta Mater. 56 (2008) p.3422.

[4] C.K. Sudbrack, K.E. Yoon, R.D. Noebe and D.N. Seidman, Acta Mater. 54 (2006) p.3199.

[5] C.K. Sudbrack, R.D. Noebe and D.N. Seidman, Acta Mater. 55 (2007) p.119.

[6] C. Schmuck, P. Caron, A. Hauet and D. Blavette, Phil. Mag. A 76 (1997) p.527.

[7] C. Schmuck, F. Danoix, P. Caron, A. Hauet and D. Blavette, Appl. Surf. Sci. 94-95 (1996) p.273.

[8] C. Pareige-Schmuck, F. Soisson and D. Blavette, Mater. Sci. Eng. A 250 (1998) p.99.

[9] C. Pareige, F. Soisson, G. Martin and D. Blavette, Acta Mater. 47 (1999) p.1889.

[10] C.K. Sudbrack, R.D. Noebe and D.N. Seidman, Phys. Rev. B 73 (2006) p.212101.

[11] J.H. Bunton, J.D. Olson, D.R. Lenz and T.F. Kelly, Microsc. Microanal. 13 (2007) p.418.

[12] D.N. Seidman, Annu. Rev. Mater. Res. 37 (2007) p.127.

[13] T.F. Kelly and M.K. Miller, Rev. Scient. Instrum. 78 (2007) p.031101/1.

[14] Z. Mao, S.B. Sinnott, G. Martin and D.N. Seidman, in press.

[15] S.S. Bajikar, D.J. Larson, T.F. Kelly and P.P. Camus, Ultramicroscopy 65 (1996) p.119.

[16] T.F. Kelly, P.P. Camus, D.J. Larson, L.M. Holzman and S.S. Bajikar, Ultramicroscopy 62 (1996) p.29.

[17] T.F. Kelly and D.J. Larson, Mater. Charact. 44 (2000) p.59.

[18] D.N. Seidman, Rev. Scient. Instrum. 78 (2007) p.030901/1. 
[19] Y. Zhou, C. Booth-Morrison and D.N. Seidman, Microsc. Microanal. 14 (2008) p.571.

[20] C.K. Sudbrack, D. Isheim, R.D. Noebe, N.S. Jacobson and D.N. Seidman, Microsc. Microanal. 10 (2004) p.355.

[21] O.C. Hellman, J.A. Vandenbroucke, J. Rüsing, D. Isheim and D.N. Seidman, Microsc. Microanal. 6 (2000) p.437.

[22] O.C. Hellman, J. Blatz du Rivage and D.N. Seidman, Ultramicroscopy 95 (2003) p.199.

[23] L.G. Parratt, Probability and Experimental Errors in Science, John Wiley, New York, 1966.

[24] D. Blavette, E. Cadel, C. Pareige, B. Deconihout and P. Caron, Microsc. Microanal. 13 (2007) p.464.

[25] B. Sundman, B. Jansson and J.O. Andersson, CALPHAD 9 (1985) p.153.

[26] N. Saunders, in Proceedings of the International Symposium on Superalloys, R.D. Kissinger, D.J. Deye, D.L. Anton, A.D. Cetel, M.V. Nathal, T.M. Pollock and D.A. Woodford, eds., TMS, Warrendale, PA, 1996, p.101.

[27] N. Dupin, I. Ansara and B. Sundman, CALPHAD 25 (2001) p.279.

[28] C.K. Sudbrack, K.E. Yoon, Z. Mao, R.D. Noebe, D. Isheim and D.N. Seidman, in Electron Microscopy: Its Role in Materials Science, the Mike Meshii Symposium, J.R. Weertman, M.E. Fine, K.T. Faber, W. King and P. Liaw, eds., TMS, San Diego, CA, 2003, p.43.

[29] A. Borgenstam, A. Engstrom, L. Hoglund and J. Agren, J. Phase Equilib. 21 (2000) p.269.

[30] C.E. Campbell, W.J. Boettinger and U.R. Kattner, Acta Mater. 50 (2002) p.775.

[31] R.A. Ricks, A.J. Porter and R.C. Ecob, Acta Metall. 31 (1983) p.43.

[32] A.C. Lund and P.W. Voorhees, Acta Mater. 50 (2002) p. 2585.

[33] A.J. Ardell, R.B. Nicholson and J.D. Eshelby, Acta Metall. 14 (1966) p.1295.

[34] Z. Mao, C.K. Sudbrack, K.E. Yoon, G. Martin and D.N. Seidman, Nature Mater. 6 (2006) p.210.

[35] M.J. Stowell, Mater. Sci. Tech. 18 (2002) p.139.

[36] G. Martin, in Solid State Phase Transformation in Metals and Alloys, Les Éditions de Physique, Orsay, France, 1978, p.337.

[37] K.C. Russell, Adv. Colloid Interface Sci. 13 (1980) p.205.

[38] R. Wagner, R. Kampmann and P.W. Voorhees, in Phase Transformations in Materials, G. Kostorz, ed., Wiley-VCH, Weinheim, 2001, p.314.

[39] D. Kashchiev, Nucleation: Basic Theory and Applications, Elsevier Science, Oxford, 2000.

[40] Y. Brechet and G. Martin, C. R. Phys. 7 (2006) p.959.

[41] F. Soisson and G. Martin, Phys. Rev. B 62 (2000) p.203.

[42] R.D. Doherty, in Physical Metallurgy, H.P. Cahn, ed., North-Holland, Amsterdam, 1996, p.1364.

[43] I.S. Servi and D. Turnbull, Acta Metall. 14 (1966) p.161.

[44] A.J. Ardell, Acta Metall. 16 (1968) p.511.

[45] J.W. Cahn, J. Chem. Phys. 30 (1959) p.1121.

[46] J.W. Cahn and J.E. Hilliard, J. Chem. Phys. 28 (1958) p.258.

[47] J.W. Cahn and J.E. Hilliard, J. Chem. Phys. 31 (1959) p.688.

[48] J.W. Christian, Theory of Transformations in Metals and Alloys, Part 1, Pergamon Press, Oxford, 2002.

[49] S.V. Prikhodko, J.D. Carnes, D.G. Isaak and A.J. Ardell, Scripta Mater. 38 (1997) p.67.

[50] C. Stassis, F.X. Kayser, C.K. Loong and D. Arch, Phys. Rev. B 24 (1981) p.3048.

[51] G.B. Olson, H.-J. Jou, J. Jung, J.T. Sebastian, A. Misra, I. Locci and D. Hull, in Proceedings of the International Symposium on Superalloys, R.C. Reed, K.A. Green, P. Caron, T.P. Gabb, M.G. Fahrmann, E.S. Huron and S.A. Woodward, eds., TMS, Warrendale, PA, 2008, p.923. 
[52] S.H. Zhou, Y. Wang, J.Z. Zhu, T. Wang, L.Q. Chen, R.A. MacKay and Z.-K. Liu, in Proceedings of the International Symposium on Superalloys, K.A. Green, T.M. Pollock, H. Harada, T.E. Howson, R.C. Reed, J.J. Schirra and S. Walston, eds., TMS, Champion, PA, 2004, p.969.

[53] A.J. Ardell, Acta Metall. 15 (1967) p.1772.

[54] E.A. Marquis and D.N. Seidman, Acta Mater. 53 (2005) p.4259.

[55] S.Q. Xiao and P. Haasen, Acta Metall. Mater. 39 (1991) p.651.

[56] C. Booth-Morrison, Y. Zhou, Z. Mao, R.D. Noebe and D.N. Seidman, 2009, in press.

[57] R. Wagner, R. Kampmann and P.W. Voorhees, Homogeneous Second-Phase Precipitation, in Phase Transformations in Materials, G. Kostorz, ed., Wiley-VCH, Weinheim, 2001.

[58] C. Zener, J. Appl. Phys. 20 (1949) p.950.

[59] F.S. Ham, J. Appl. Phys. 30 (1959) p.1518.

[60] A.J. Ardell, Mater. Sci. Eng., A A238 (1997) p.108.

[61] A. Baldan, J. Mater. Sci. 37 (2002) p.2379.

[62] A. Baldan, J. Mater. Sci. 37 (2002) p.2171.

[63] D.J. Rowenhorst, J.P. Kuang, K. Thornton and P.W. Voorhees, Acta Mater. 54 (2006) p.2027.

[64] I.M. Lifshitz and V.V. Slyozov, J. Phys. Chem. Solid. 19 (1961) p.35.

[65] C. Wagner, Z. Electrochem 65 (1961) p.581.

[66] P.W. Voorhees, Annu. Rev. Mater. Sci. 22 (1992) p.197.

[67] L. Ratke and P.W. Voorhees, Growth and Coarsening, Ripening in Material Processing, Springer-Verlag, Berlin, 2002.

[68] J.E. Morral and G.R. Purdy, Scripta Metall. Mater. 30 (1994) p.905.

[69] A. Umantsev and G.B. Olson, Scripta Metall. Mater. 29 (1993) p.1135.

[70] C.J. Kuehmann and P.W. Voorhees, Metall. Mater. Trans. A 27 (1996) p.937.

[71] R. Kampmann and R. Wagner, in Decomposition of Alloys: the Early Stages, P. Haasen, V. Gerold, R. Wagner and M.F. Ashby, eds., Pergamon Press, Oxford, 1984, p.91.

[72] J.S. Langer and A.J. Schwartz, Phys. Rev. A 21 (1980) p.948.

[73] C.K. Sudbrack, T.D. Ziebell, R.D. Noebe and D.N. Seidman, Acta Mater. 56 (2008) p.448.

[74] K.E. Yoon, R.D. Noebe and D.N. Seidman, Acta Mater. 55 (2007) p.1145.

[75] C. Booth-Morrison, R.D. Noebe and D.N. Seidman, Acta Mater. 57 (2008) p.909.

[76] K. Thornton, J. Agren and P.W. Voorhees, Acta Mater. 51 (2003) p.5675.

[77] J.Z. Zhu, T. Wang, A.J. Ardell, S.H. Zhou, Z.K. Liu and L.Q. Chen, Acta Mater. 52 (2004) p.2837. 